\title{
Optimization of Extraction Process of Bioactive Compounds from Bene Hull Using Subcritical Water
}

\author{
Rezvan Shaddel, Abdolmajid Maskooki, Mohammad Hossein Haddad-Khodaparast, Sodeif Azadmard-Damirchi, \\ Morteza Mohamadi, and Bahram Fathi-Achachlouei
}

Received November 23, 2013; revised March 10, 2014; accepted March 20, 2014; published online October 31, 2014

(C) KoSFoST and Springer 2014

\begin{abstract}
Bene hull contains antioxidant components. Optimum conditions for bioactive compound extraction processes from Bene hull using subcritical water with response surface methodology (RSM) were obtained. Temperature $\left(110-200^{\circ} \mathrm{C}\right)$, processing time $(30-60 \mathrm{~min})$, and the water to Bene hull ratio (10:1-50:1) were the investigated factors. The optimal conditions for maximizing the antioxidant activity were $196.8^{\circ} \mathrm{C}$ for $52.6 \mathrm{~min}$ and a ratio of 43.6:1 for water to Bene hull. Under these conditions, the amount of polyphenolic compounds, the reduction power (RP) $\left(\mathrm{EC}_{50}\right)$, and the $\mathrm{DPPH}$ free radical scavenging activity (RSA) $\left(\mathrm{EC}_{50}\right)$ were predicted to be $2,284 \mathrm{mg}$ of gallic acid/100 g of Bene hull, $0.2002 \mathrm{mg} / \mathrm{mL}$, and 0.6284 $\mathrm{mg} / \mathrm{mL}$, respectively. HPLC analysis was used to identify the main phenolic compounds. The subcritical water extraction technique could be used as a beneficial method to obtain bioactive compounds from Bene hull.
\end{abstract}

Keywords: Bene hull, antioxidant, reduction power,

Rezvan Shaddel

Department of Food Science and Technology, Faculty of Agriculture, University of Tabriz, P.O. Box 91735-147 Tabriz, Iran

Mohammad Hossein Haddad-Khodaparast

Department of Food Science and Technology, Ferdowsi University of Mashhad (FUM), Mashhad, 91775-1163, Iran

Abdolmajid Maskooki, Morteza Mohamadi $(\bowtie)$

Department of Food Processing, Research Institute of Food Science and Technology (RIFST), P.O. Box 91735-147 Mashhad, Iran

Tel: +985115425307; Fax: +985115003150

E-mail: mohamadi2003@yahoo.com

Sodeif Azadmard-Damirchi

Department of Food Science and Technology, University of Tabriz, P.O. Box 91735-147 Tabriz, Iran

Bahram Fathi-Achachlouei

Faculty of Agricultural Sciences, University of Mohaghegh Ardabili, P.O. Box 56199-11367 Ardabil, Iran radical scavenging, subcritical water

\section{Introduction}

The positive effect of natural antioxidants on human health has been illustrated in recent years (1). On the other hand, the detrimental effects of synthetic antioxidants, such as butylated hydroxytoluene (BHT) and butylated hydroxyanisole (BHA), on human health have led scientists to search for new natural antioxidant resources. The toxicity of synthetic antioxidants and suspected actions as promoters of carcinogenesis have been investigated (2). However, a demand for alternative natural and safe sources of food antioxidants has been created and research into natural antioxidants, particularly from plant origins, has developed in recent years (3).

Bene (Pistacia atlantica subsp. mutica) is a wild variety of pistachio and a native plant that grows in the Zagross region of Iran at 600-3,000 m above sea level (4). The fruit is round to oval, somewhat flat, and a dark green to yellow or brownish color and $0.5-0.7 \mathrm{~cm}$ in diameter. The Bene kernel is covered with a hard wooden shell that can easily be removed by hand. The soft hull comprises $24 \%$ of the whole fruit (25\% of the kernel and $51 \%$ of the hard shell) and contains up to $30 \%$ oil (5). A few investigations have been carried out on the antioxidant properties of Bene (611).

Subcritical water is defined as a region of the condensed phase of water between $100^{\circ} \mathrm{C}$ (boiling point of water) and $374^{\circ} \mathrm{C}$ (critical point of water) with pressure proportional to maintain a liquid state (10). This condition is also called pressurized low polarity water (PLPW) or pressurized hot water (PHW) (11). The dielectric constant (eee) of water is 80 at $25^{\circ} \mathrm{C}$ and decreases to 27 when the temperature rises 
to $250^{\circ} \mathrm{C}$. Methanol has en eee value of 33 and ethanol has an eee value of 24 at $25^{\circ} \mathrm{C}$. Subcritical water behaves like certain organic solvents that can dissolve a wide range of medium and low polarity analysts (12).

In recent years, several novel extraction methods, including pressurized-hot water extraction (PHWE), supercritical fluids extraction (SFE) mainly with $\mathrm{CO}_{2}$, microwave assisted extraction (MWE), ultrasonication assisted extraction (USE), pulse electric field assisted extraction (PEFE), and high pressure assisted extraction (HPE) have been developed for extraction from different substances. These methods are green technologies that exhibit a number of advantages over conventional extraction techniques, including hydro-distillation and organic solvent extraction, simplicity, a higher selectivity, a high yield and productivity (time, cost and energy saving), higher extract quality, and environmental safety (13). SWE has been successfully applied to extraction of many antioxidants and functional compounds from natural resources (13-15). SWE has been used to extract nutraceutical compounds from citrus pomace (16) and from Centella asiatica (17), antioxidant compounds from Sea buckthorn leaves (18), onion (Allium cepa L.) peels (19), and rosemary plants (20), phenolic antioxidants from the fruit of Terminaliachebula Retz (21) and pomegranate seed residues (22), and even proanthocyanidins from wine-related products (23).

Optimization of extraction conditions to achieve stability and high value of antioxidant activities are important issues. Response surface methodology (RSM) is a common approach for optimization of complex and multi-variable research problems (24). Many researchers have used this method to optimize different processes $(22,25-27)$. One of the advantages of RSM is the possibility of determining interactions among independent variables (28). The main goals of this research were first, to determine optimized conditions for Bene hull subcritical water extraction based on antioxidant activities and second, to compare the subcritical water and hot water extraction methods.

\section{Materials and Methods}

Samples and reagents Fruits of Pistacia atlantica were collected from the Marvdasht region in Fars province (Iran) in November of 2010 and stored at $-18^{\circ} \mathrm{C}$ to minimize oxidation of compounds during experiments. The fruit hull was separated immediately before each treatment. Deionized water was used as a solvent during SCW operations. BHT, L-ascorbic acid, and gallic acid (GA) were purchased from a local agency of Sigma-Aldrich Chemicals (St. Louis, MO, USA). DPPH, Folin-Ciocalteu reagent (FCR), potassium ferricyanide, ferric chloride, and sodium carbonate were obtained from Merck (Darmstadt, Germany). Whatman
No. 4 filter paper and trichloro acetic acid were obtained from VWR International (Mississauga, ON, Canada). All other chemicals and solvents (analytical grade) used were purchased from Beijing Chemical Co. (Beijing, China).

Subcritical water extraction Extraction of juice from Bene hull was carried out using a laboratory-built apparatus (Fig. 1). The system consisted of a deionized water feed tank, a high pressure metering pump (Comet type: MTP AX 2/70 m) to deliver water and solvent through the system, an extraction vessel $(140 \mathrm{~mL})$, ferro-nickel heating wires wrapped around the extraction vessel to supply the required temperature, and a temperature control unit. The extraction process was carried out after adjusting the temperature and pressure $\left(110^{\circ} \mathrm{C}, 2\right.$ bars, $155^{\circ} \mathrm{C}, 5$ bars, and $200^{\circ} \mathrm{C}, 15$ bars). The minimum pressure was applied to maintain the condensed phase of water. The extraction vessel was heated before each experiment, then the temperature was changed according to the desired temperature for extraction. The duration of initial heating was automatically
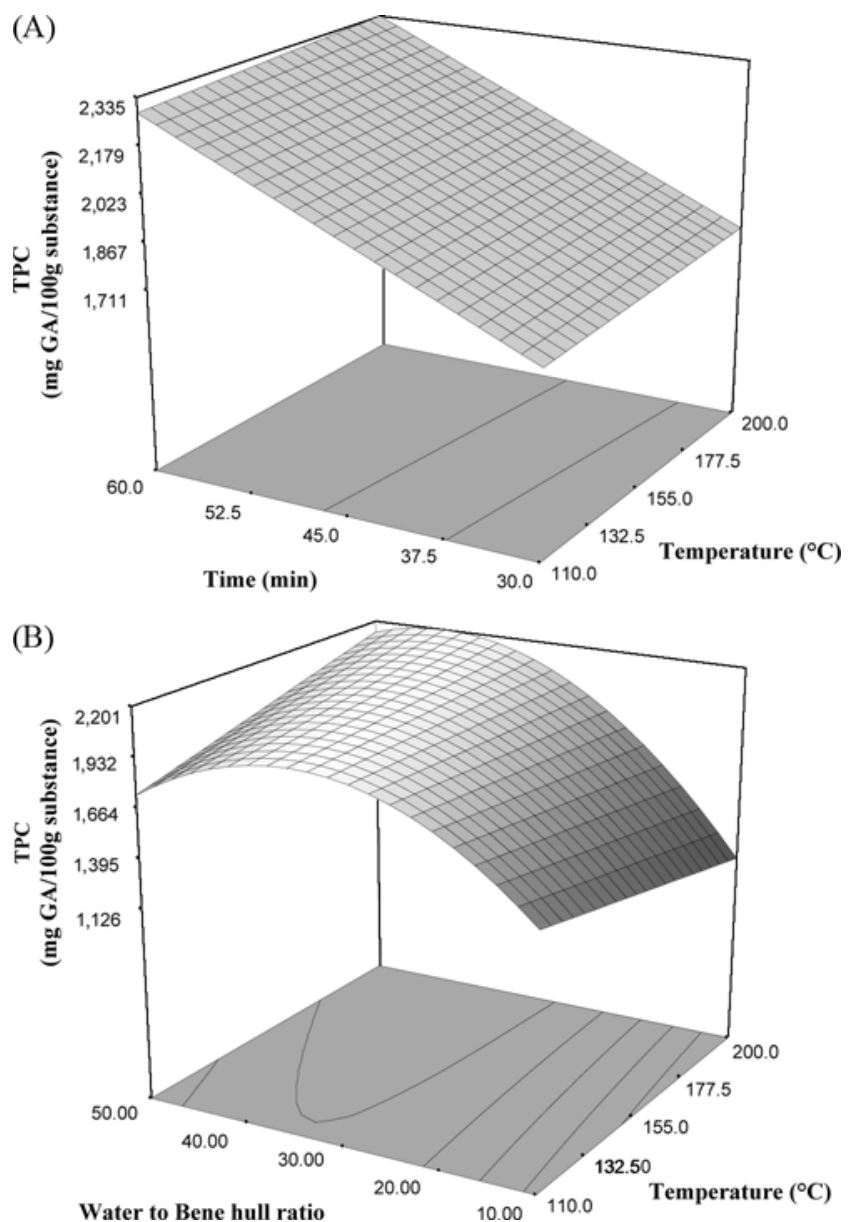

Fig. 1. Response surfaces and contour plots of the total phenolics of Bene hull SWE extracts as a function of (A) extraction time and temperature and (B) extraction temperature and water to the Bene hull ratio. 
controlled by the thermo control device. Times of 5, 7 and $9 \mathrm{~min}$ of initial heating were used when the extraction temperature was set at 110,155 , and $200^{\circ} \mathrm{C}$, respectively. After the extraction procedure, the obtained extract was filtered through Whatman No.4 filter paper, then measured for volume. The extract was concentrated at a constant weight by evaporation of water under a vacuum. Between each extraction process, the system was completely rinsed using ethanol and subsequently with deionized water to remove any residual products.

Hot water extraction $\left(8^{\circ} \mathbf{C}\right)$ Hot water extraction was carried out using $5 \mathrm{~g}$ of Bene hull in $100 \mathrm{~mL}$ of water (1:20), at $85^{\circ} \mathrm{C}$ and $30 \mathrm{~min}$ on a platform shaker as a conventional extraction method for comparison. The extracted solution was filtered and lyophilized. Analysis of extracts was carried out immediately after freeze-drying (29).

Determination of the total phenolic content (TPC) The total phenolic content was determined using FCR as described by Singh et al. (30). An amount of $0.5 \mathrm{~mL}$ of each sample was mixed with $2.5 \mathrm{~mL}$ of FCR (diluted 1:10 using distilled water). Then, $2 \mathrm{~mL}$ of $7.5 \% \mathrm{Na}_{2} \mathrm{CO}_{3}(\mathrm{w} / \mathrm{v})$ was added to the mixture. The prepared solutions were incubated at room temperature in the dark for $30 \mathrm{~min}$. The absorbance of the mixtures was measured at $765 \mathrm{~nm}$. GA was used to produce a standard curve $(0-200 \mathrm{mg} / \mathrm{L})$. Measurements of the phenolic compounds were expressed as mg of gallic acid equivalents (GAE)/100 g of the dry weight of plant material.

Reduction power assay The reducing power was measured following the method of Barros et al. (31). According to this method, $2.5 \mathrm{~mL}$ of the test solution (a concentration of $0.1-1.0 \mathrm{mg} / \mathrm{mL}$ ) was mixed with $2.5 \mathrm{~mL}$ of a $200 \mathrm{mM}$ sodium phosphate buffer $(\mathrm{pH} 6.6)$ and 2.5 $\mathrm{mL}$ of $1 \%$ potassium ferri cyanide $\left[\mathrm{K}_{3} \mathrm{Fe}(\mathrm{CN})_{6}\right]$. The mixture was incubated at $50^{\circ} \mathrm{C}$ for $20 \mathrm{~min}$. Then, the mixture was acidified using $2.5 \mathrm{~mL}$ of $10 \%$ trichloro acetic acid (w/ $\mathrm{v}$ ), then centrifuged at 1,400 $\mathrm{g}$ for $8 \mathrm{~min}$ (E200 Labofuge centrifuge). The supernatant $(5 \mathrm{~mL})$ was mixed with $5 \mathrm{~mL}$ of distilled water and $1 \mathrm{~mL}$ of $\mathrm{FeCl}_{3}(0.1 \%)$, and the absorbance was measured at $700 \mathrm{~nm}$ using a UV spectrophotometer (Jenway 6105). The extract concentration that produced a median effective absorbance value ( 0.5 of absorbance (EC50) was calculated from the absorbance graph at 700 $\mathrm{nm}$ versus the extract concentration. Ascorbic acid was used for comparison.

DPPH free-radical scavenging assay The DPPH freeradical scavenging median effective value $\left(\mathrm{IC}_{50}\right)$ was estimated using the method of Rodriguez-Meizoso et al. (2), with some modification. BHT was used as a positive control (2). Briefly, $23.5 \mathrm{mg}$ of DPPH was dissolved in $100 \mathrm{~mL}$ of methanol. This solution was diluted at a ratio of 1:10 using methanol. During the assay, $0.1 \mathrm{~mL}$ of a test solution (a concentration of $0.5-2.5 \mathrm{mg} / \mathrm{mL}$ ) was mixed with $3.9 \mathrm{~mL}$ of a DPPH solution. The reaction was completed after $4 \mathrm{~h}$ at room temperature and the absorbance was measured against the blank reagent at $516 \mathrm{~nm}$ using a UV/ VIS Spectrophotometer (Jenway). The purple-colored, stable free radical DPPH was reduced to yellow diphenyl picryl hydrazine when antioxidant was added. The scavenging capability of DPPH radicals was calculated using Eq. (1):

$$
\text { Scavenging effect }(\%)=\left[1-\left(\mathrm{ABS}_{\text {sample }} / \mathrm{ABS}_{\text {control }}\right)\right]
$$

The percentage of scavenging capability (S.C\%) was plotted against the extract concentrations and a polynomial regression curve was established in order to calculate the $\mathrm{EC}_{50}$ value $(\mathrm{mg} / \mathrm{mL})$, which was the concentration of the extract that inhibited DPPH by $50 \%$. The lower the $\mathrm{EC}_{50}$ value, the higher the antioxidant power.

HPLC-DAD analysis of the extracts Identification of polyphenolic compounds was performed using high performance ternary gradient liquid chromatography (HPLC; Young lin, Korea), equipped with a $\mathrm{C} 18$ reverse-phase column $(4.6 \mathrm{~mm} \times 25 \mathrm{~cm})$, type Spherisorb ODS- $25 \mathrm{~mm}$, $100 \mathrm{~A}^{\circ}$, with a spectrophotometric UV detector at $280 \mathrm{~nm}$ and an integrator. Syringic acid was used as an internal standard. The mobile phase was (A) water and $0.2 \% \mathrm{H}_{3} \mathrm{PO}_{4}$ (V/V), (B) methanol, and (C) acetonitrile. Elution solvents should be de-gassed. The gradient conditions were $0 \mathrm{~min}$ at $96 \% \mathrm{~A}$ and $2 \% \mathrm{~B} ; 40 \mathrm{~min}$ at $50 \% \mathrm{~A}$ and $25 \% \mathrm{~B}$; $45 \mathrm{~min}$ at $40 \% \mathrm{~A}$ and $30 \% \mathrm{~B} ; 60 \mathrm{~min}$ at $0 \% \mathrm{~A}$ and $50 \%$ B; 70 min at $0 \% \mathrm{~A}$ and $50 \% \mathrm{~B} ; 72 \mathrm{~min}$ at $96 \% \mathrm{~A}$ and $2 \%$ $\mathrm{B}$; and 82 min at $96 \% \mathrm{~A}$ and $2 \% \mathrm{~B}$. The total run time was $82 \mathrm{~min}$ and the injected volume was $20 \mu \mathrm{L}$. The flow rate was kept at $1 \mathrm{~mL} / \mathrm{min}$ (32). A total of 6 phenolic compounds, including epicatechin, chlorogensaure, kaffesaure, flavanomarein, ethyl vanillin, and apigenin 7-glucoside were identified and quantified.

Statistical analysis Optimized experiments were carried out according to a central composite face centered design with the 3 independent variables extraction temperature $\left(110-200^{\circ} \mathrm{C}\right)$, extraction time $(30-60 \mathrm{~min})$, and the water to Bene hull ratio (10:1-50:1). RSM was applied to the experimental data using the commercial statistical package of Design-Expert version 6.0.2 (Statease Inc., Minneapolis, MN, USA). The complete design consisted of 20 experimental points, including 6 replications of the center point, and the experiment was carried out randomly to minimize the effects of unexplained variability on the 
observed responses. Decoded and coded values of the independent variables and the experimental data are shown in Table 1. In order to predict the optimal point, a secondorder polynomial model was fitted to correlate relationships between independent variables and responses (polyphenolic compounds, reducing power, and DPPH free-radical scavenging). Relationships between the 3 factors are shown in Eq. (2):

$$
\begin{aligned}
\mathrm{Y}_{\mathrm{n}}= & \beta_{0}+\beta_{1} \mathrm{X}_{1}+\beta_{2} \cdot \mathrm{X}_{2}+\beta_{3} \cdot \mathrm{X}_{3}+\beta_{11} \cdot \mathrm{X}_{1}^{2}+\beta_{22} \cdot \mathrm{X}_{2}^{2}+\beta_{33} \cdot \mathrm{X}_{3}^{2} \\
& +\beta_{12} \cdot \mathrm{X}_{1} \cdot \mathrm{X}_{2}+\beta_{13} \cdot \mathrm{X}_{1} \cdot \mathrm{X}_{3}+\beta_{23} \cdot \mathrm{X}_{2} \cdot \mathrm{X}_{3}
\end{aligned}
$$

where $Y_{n}$ is one of the 3 responses; $X_{1}, X_{2}$ and $X_{3}$ represent the independent variables, $\beta_{0}$ is a constant; $\beta_{1}, \beta_{2}$, and $\beta_{3}$ are the linear-term coefficients, $\beta_{11}, \beta_{22}$, and $\beta_{23}$ are the quadratic-term coefficients, and $\beta_{12}$ and $\beta_{13}$ are interaction coefficients.

An analysis of variance (ANOVA) was performed and the fitness of the polynomial model equation was evaluated using lack of fit (model error), coefficient of regression $\left(R^{2}\right)$, adjusted- $R^{2}$, coefficient of variation $(\mathrm{CV})$, and the Fisher test value ( $F$ value). Statistical significance of the model and model variables was determined based on an $F$ test at a probability ( $p$ ) of either 0.01 or 0.05 . The effect of variables was displayed in 3-dimensional response surfaces and 2-dimensional contour plots.

\section{Results and Discussion}

Fitting the models To fit the explanatory models and the variation of the total phenolic content, the reducing power, and radical scavenging, the sum of squares of the sequential model was analyzed. A quadratic regression model was the most appropriate model for the 3 response variables (Table 2).

Regression coefficients obtained from the ANOVA by fitting experimental data to the second order polynomial response surface models for each of the response variables $\left(\mathrm{Y}_{\mathrm{n}}\right)$, and corresponding coefficients of determination $\left(R^{2}\right)$ values are shown in Table 3 . In addition, adj- $R^{2}$ and coefficient of variation $(\mathrm{CV})$ values were calculated to check the model adequacy. $R^{2}$ values for TPC, the reducing power $\left(\mathrm{EC}_{50}\right)$, and $\mathrm{DPPH}\left(\mathrm{EC}_{50}\right)$ were $0.928,0.902$, and 0.987 , respectively. These $R^{2}$ values indicated that the regression model was suitable to explain the behavior of the system. Adjusted $R^{2}$ values were also higher than 0.8 , indicating that non-significant terms were not included in the model.

The coefficient of variation (CV) was lower than $10 \%$ for all responses (Table 3), representing good precision and reliability of the results. These models were adequate for predicting operating conditions within the ranges of the variables used.

Table 1. Coded and uncoded levels of independent variables for central composite design and, TPC, reducing power and radical

\begin{tabular}{|c|c|c|c|c|c|c|c|c|c|}
\hline \multirow{2}{*}{ Exp. } & \multicolumn{3}{|c|}{ Coded level } & \multicolumn{3}{|c|}{ Independent variables (actual values) } & \multicolumn{3}{|c|}{ Dependent variables ${ }^{1)}$ (experimental data) } \\
\hline & $\mathrm{X}_{1}$ & $\mathrm{X}_{2}$ & $\mathrm{X}_{3}$ & Temperature $\left({ }^{\circ} \mathrm{C}\right)$ & Time (min) & Ratio & TPC & $\mathrm{RP}$ & RSA \\
\hline 1 & +1 & +1 & +1 & 200 & 60 & 50 & 2203 & 245.5 & 646.4 \\
\hline 2 & 0 & 0 & +1 & 155 & 45 & 50 & 2113 & 259.6 & 700.2 \\
\hline 3 & -1 & +1 & +1 & 110 & 60 & 50 & 1923 & 343.6 & 1461 \\
\hline 4 & 0 & 0 & 0 & 155 & 45 & 30 & 1991 & 255.2 & 782.7 \\
\hline 5 & +1 & -1 & +1 & 200 & 30 & 50 & 2006 & 255.0 & 777.7 \\
\hline 6 & 0 & 0 & 0 & 155 & 45 & 30 & 1991 & 223.7 & 740.6 \\
\hline 7 & 0 & 0 & 0 & 155 & 45 & 30 & 1797 & 233.2 & 698.3 \\
\hline 8 & 0 & 0 & -1 & 155 & 45 & 10 & 1423 & 234.7 & 639.8 \\
\hline 9 & +1 & +1 & -1 & 200 & 60 & 10 & 1714 & 203.4 & 676.8 \\
\hline 10 & -1 & +1 & -1 & 110 & 60 & 10 & 1644 & 265.5 & 1445 \\
\hline 11 & 0 & +1 & 0 & 155 & 60 & 30 & 2283 & 302.8 & 782.0 \\
\hline 12 & 0 & 0 & 0 & 155 & 45 & 30 & 2148 & 230.6 & 665.8 \\
\hline 13 & +1 & -1 & -1 & 200 & 30 & 10 & 489 & 381.0 & 1005 \\
\hline 14 & 0 & 0 & 0 & 155 & 45 & 30 & 2138 & 253.8 & 723.9 \\
\hline 15 & 0 & -1 & 0 & 155 & 30 & 30 & 1842 & 336.4 & 886.0 \\
\hline 16 & -1 & -1 & -1 & 110 & 30 & 10 & 1118 & 210.5 & 1418 \\
\hline 17 & -1 & -1 & +1 & 110 & 30 & 50 & 1440 & 249.8 & 1426 \\
\hline 18 & 0 & 0 & 0 & 155 & 45 & 30 & 1993 & 239.8 & 784.2 \\
\hline 19 & +1 & 0 & 0 & 200 & 45 & 30 & 2003 & 213.1 & 685.2 \\
\hline 20 & -1 & 0 & 0 & 110 & 45 & 30 & 2045 & 230.6 & 1450 \\
\hline
\end{tabular}
scavenging of the superheated water extracts

${ }^{1)} \mathrm{TPC}$, total phenolic content (mg GAE/100 g of Bene hull); RP, reducing power $\left(\mathrm{EC}_{50}, \mathrm{mg} / \mathrm{L}\right) ; \mathrm{RSA}, \mathrm{DPPH}$ radical scavenging $\left(\mathrm{EC}_{50}, \mathrm{mg} / \mathrm{L}\right)$ 
Table 2. Sequential model sum of squares for total phenolic content, reducing power, and radical scavenging

\begin{tabular}{|c|c|c|c|c|c|c|c|}
\hline \multirow{2}{*}{ Source } & \multirow{2}{*}{$\mathrm{DF}$} & \multicolumn{2}{|c|}{ Total phenolic content } & \multicolumn{2}{|c|}{ Reducing power } & \multicolumn{2}{|c|}{ Radical scavenging } \\
\hline & & Sum of squares & $p>F$ & Sum of squares & $p>F$ & Sum of squares & $p>F$ \\
\hline Mean & & $6.59 \times 10^{07}$ & & $1.33 \times 10^{06}$ & & $1.69 \times 10^{07}$ & \\
\hline Linear & 11 & $1.92 \times 10^{06}$ & 0.004 & 858.6 & 0.953 & $1.19 \times 10^{06}$ & 0.001 \\
\hline Interaction & 8 & $4.12 \times 10^{05}$ & 0.250 & $2.45 \times 10^{04}$ & 0.007 & $4.91 \times 10^{04}$ & 0.822 \\
\hline Quadratic & 5 & $9.02 \times 10^{05}$ & 0.001 & $1.28 \times 10^{04}$ & 0.002 & $6.74 \times 10^{05}$ & $<0.001$ \\
\hline Cubic & 1 & $1.38 \times 10^{05}$ & 0.242 & $2.61 \times 10^{03}$ & 0.146 & $1.45 \times 10^{04}$ & 0.216 \\
\hline Residual & & $1.13 \times 10^{05}$ & & $1.54 \times 10^{03}$ & & $1.09 \times 10^{04}$ & \\
\hline Total & & $6.94 \times 10^{07}$ & & $1.378 \times 10^{06}$ & & $1.87 \times 10^{07}$ & \\
\hline
\end{tabular}

Table 3. Second order response model constants and regression analysis for TPC, Reduction Power and Radical Scavenging of the superheated water extracts

\begin{tabular}{|c|c|c|c|c|}
\hline Term & Coefficient $^{1)}$ & $\mathrm{TPC}^{2)}$ & $\mathrm{RP}$ & RSA \\
\hline Intercept & $\beta_{0}$ & $-704.5^{* * 3)}$ & $+1.80 * *$ & $+6095 * *$ \\
\hline $\mathrm{X}_{1}$ (Temperature) & $\beta_{1}$ & +3.979 & +8.57 & $-53.39 * *$ \\
\hline $\mathrm{X}_{2}$ (Time) & $\beta_{2}$ & $+38.49 * *$ & -19.61 & $-31.56^{*}$ \\
\hline $\mathrm{X}_{3}$ (water to the Bene hull ratio) & $\beta_{3}$ & $+57.22 * *$ & +1.797 & +10.72 \\
\hline $\mathrm{X}_{1}^{2}$ (Temperature $)$ & $\beta_{11}$ & -0.041 & $-0.016^{*}$ & $+0.166^{* *}$ \\
\hline $\mathrm{X}_{2}^{2}$ (Time) & $\beta_{22}$ & -0.198 & $+0.291 * *$ & $+0.451 * *$ \\
\hline $\mathrm{X}_{3}^{2}$ (water to the Bene hull ratio) & $\beta_{33}$ & $-0.848 * *$ & -0.017 & -0.156 \\
\hline $\mathrm{X}_{1}$ (Temperature $) \times \mathrm{X}_{2}$ (Time) & $\beta_{12}$ & +0.076 & $-0.062 * *$ & $-0.096 * *$ \\
\hline $\mathrm{X}_{1}$ (Temperature $) \times \mathrm{X}_{3}$ (water to the Bene hull ratio) & $\beta_{13}$ & $+0.195 *$ & $-0.028 * *$ & -0.039 \\
\hline \multirow[t]{7}{*}{$\mathrm{X}_{2}$ (Time) $\times \mathrm{X}_{3}$ (water to the Bene hull ratio) } & $\beta_{23}$ & $-0.446^{*}$ & $+0.086^{* *}$ & +0.085 \\
\hline & $\mathrm{R}^{2}$ & 0.928 & 0.902 & 0.987 \\
\hline & $\operatorname{Adj}-R^{2}$ & 0.863 & 0.814 & 0.975 \\
\hline & $F$ & $14 / 31$ & $10 / 23$ & $83 / 52$ \\
\hline & $p$ & $<0.001^{* *}$ & $0.0006 * *$ & $<0.001 * *$ \\
\hline & Standard Error & 0.222 & 0.075 & 0.383 \\
\hline & $\mathrm{CV}$ & 8.73 & 7.88 & 5.49 \\
\hline
\end{tabular}

${ }^{1)} Y_{n}=\beta_{0}+\beta_{1} X_{1}+\beta_{2} X_{2}+\beta_{3} X_{3}+\beta_{11} X_{1}^{2}+\beta_{22} X_{2}^{2}+\beta_{33} X_{3}^{2}+\beta_{12} X_{1} X_{2}+\beta_{13} X_{1} X_{3}+\beta_{23} X_{2} X_{3}$

${ }^{2)} \mathrm{TPC}$, total phenolic content (mg GAE/100 $\mathrm{g}$ of Bene hull); RP, reducing power $\left(\mathrm{EC}_{50}, \mathrm{mg} / \mathrm{L}\right) ; \mathrm{RSA}, \mathrm{DPPH}$ radical scavenging $\left(\mathrm{EC}_{50}, \mathrm{mg} / \mathrm{L}\right)$

3)* Significant at $p<0.05$; ** significant at $p<0.01$

The total phenolic compound contents The response surface quadratic model for the polyphenolic content was statistically significant $(p<0.01)$, while the lack of fit test showed no significant difference $(p>0.05)$ (Table 2). Therefore, the regression model was in good agreement with the experimental results. The linear effect of time (B) and water to the Bene hull ratio $(\mathrm{C})$, and also the quadratic effect of water to the Bene hull ratio $\left(\mathrm{C}^{2}\right)$ were highly significant $(p<0.01)$. Among the interaction terms, the extraction temperature and water to the Bene hull ratio $(\mathrm{AC})$, and the extraction time and water to the Bene hull ratio $(\mathrm{BC})$ were significant $(p<0.05)$ for total phenolic compound contents (Fig. 2). The values of the coefficient of determination $\left(R^{2}=0.928\right)$ and the adjusted coefficient of determination (Adjusted $R^{2}=0.863$ ) were reasonably close to 1 , indicating a high degree of correlation between the observed and predicted values (Table 3). Equation (3) shows the reduced quadratic model for polyphenolic compound content prediction.

$$
\begin{aligned}
\mathrm{Y}= & -48.57-5.31 \mathrm{X}_{1}+32.54 \mathrm{X}_{2}+68.72 \mathrm{X}_{3}-1.04 \mathrm{X}_{3}^{2} \\
& +0.19 \mathrm{X}_{1} \mathrm{X}_{3}-0.45 \mathrm{X}_{2} \mathrm{X}_{3}
\end{aligned}
$$

Phenolic compounds modulate the occurrence and intensity of Millard and caramelization reactions (33). The 3-dimensional surfaces and contour plots of the effects of the extraction temperature, time, and ratio of water to Bene hull on the polyphenolic content of Bene hull conducted with subcritical water extracts are shown in Fig. 1. The purpose of optimization of this variable was to achieve a higher polyphenolic compound content. In other words, more polyphenolic compounds indicated a higher extract antioxidant capacity. The extraction time affected the polyphenolic compound content in a linear manner (Fig. $2 \mathrm{~A})$. However, there was no significant $(p>0.05)$ effect for the temperature term. The polyphenolic compound content was increased with an increase in the extraction time. A significant $(p<0.01)$ effect was observed for the extraction time $(p<0.05)$. The effect of the extraction temperature and 

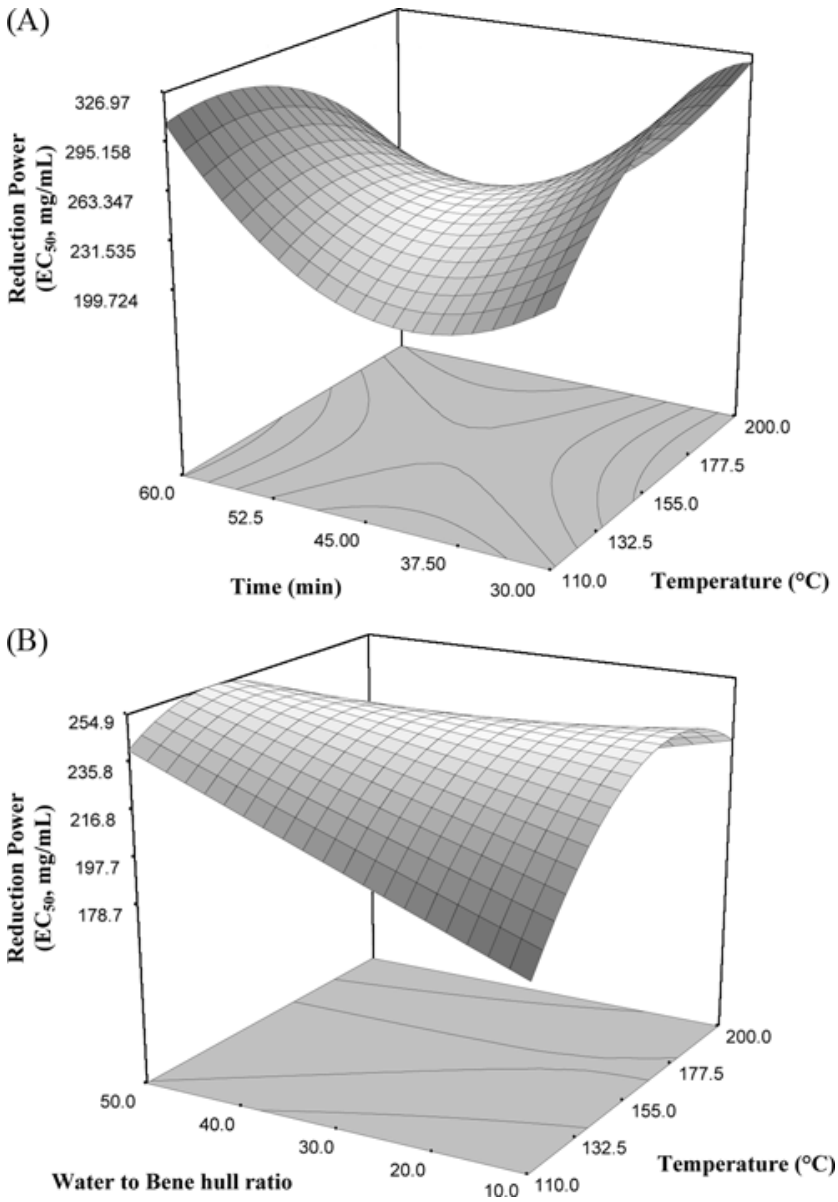

Fig. 2. Response surfaces and contour plots of the reducing power $\left(\mathrm{EC}_{50}\right)$ of Bene hull SWE extracts as a function of (A) extraction time and temperature and $(B)$ extraction temperature and water to the Bene hull ratio.

water to the Bene hull ratio (AC) on TPC are shown in Fig. 1B. The extraction time had no significant $(p>0.05)$ effect on the polyphenolic compound content, while the interaction between the extraction temperature and water to the Bene hull ratio was significant $(p<0.05)$. The effect of the increase in water to the Bene hull ratio was non-linear. There was an increase in the polyphenolic compound content with an increase in the ratio of water to the Bene hull ratio at a specific level (30-1). The variables with the most effect were the linear and quadratic term of water to the Bene hull ratio $\left(\mathrm{C}\right.$ and $\left.\mathrm{C}^{2}\right)$, the linear term of the extraction time, followed by the interaction effect of the extraction temperature-water to the Bene hull ratio (AC) and the temperature-water to the Bene hull ratio $(\mathrm{BC})$. The extraction procedure was better with an increased water to Bene hull ratio.

The solvent diffusivity increased at high ratio values of water to Bene hull and the solvent was also saturated with a higher amount of extracted material. The results of this study were in agreement with Plaza et al. (34) in which it was observed that various natural substances represent different polyphenolic compound contents. Although there was no statistical difference between the polyphenolic compound content obtained using Thyme and Halopitys incurvus at 100 and $200^{\circ} \mathrm{C}(p>0.05)$, other substances showed ND differences (34). Results of this study were also in agreement with reported results of RodriguezMeizoso et al. (2) for Oregano where it was observed that the polyphenolic compound content showed no differences between different extracts. The amount of extracted phenolic compounds was similar, but the type and structure of the phenolics were different.

The increase in the ionization constant $\left(\mathrm{K}_{\mathrm{W}}\right)$ of water under subcritical conditions affects the Bene hull hydrolysis reaction. Lignin, a component of the plant cell wall, has been shown to decompose into phenols under subcritical conditions. This characteristic of water improves the extraction of phenols from fruits via a catalyzed hydrolytic degradation of the polysaccharide-lignin network of the cell wall matrix (21).

Reducing power of $\mathrm{Fe}^{+3}$ The response surface quadratic model for the reducing power was statistically significant $(p<0.05)$ whereas the lack of fit test was not significant $(p>0.05)$. The regression model was able to explain the behavior of the system (Table 2). None of the linear model terms were significant $(p>0.05)$ by themselves. Among the quadratic terms, temperature $\left(\mathrm{A}^{2}\right)$ and time $\left(\mathrm{B}^{2}\right)$ were significant $(p<0.01)$. All of the mutual interactions between independent variables, including temperature and time $(\mathrm{AB})$, temperature and water to the Bene hull ratio $(\mathrm{AC})$, and time and water to the Bene hull ratio $(\mathrm{BC})$ were also found to be significant $(p<0.01)$.

The $R^{2}$ and adj- $R^{2}$ values for the reduction power were 0.902 and 0.814 , respectively. The reduction power (Table 3) demonstrated that the relationship between reducing power and extraction parameters was quadratic with a good regression coefficient $\left(R^{2}=0.902\right)$. The relationship in a reduced quadratic model is shown in Eq. (4):

$$
\begin{aligned}
\mathrm{Y}= & -38.04+8.98 \mathrm{X}_{1}-18.56 \mathrm{X}_{2}+0.75 \mathrm{X}_{3}-0.02 \mathrm{X}_{1}^{2} \\
& +0.28 \mathrm{X}_{2}^{2}-0.062 \mathrm{X}_{1} \mathrm{X}_{2}-0.028 \mathrm{X}_{1} \mathrm{X}_{3}+0.086 \mathrm{X}_{2} \mathrm{X}_{3}
\end{aligned}
$$

The response surface and contour plots between independent variables and the reducing power of Bene hull subcritical water extracts are shown in Fig. 2. The reducing power was calculated based on $\mathrm{EC}_{50}$ values. The low absorbance of the reaction mixture indicated a high reducing power, which indicated a high antioxidant capacity. Achieving a lower $\mathrm{EC}_{50}$ value was the purpose of this variable optimization. None of the linear model terms were significant $(p>0.05)$ optimization of the reducing power.

The $\mathrm{EC}_{50}$ value was decreased when the extraction temperature and time were increased. This generally results in an increase in the reducing power. At short extraction 
times, the value of $\mathrm{EC}_{50}$ increased when the temperature increased. On the other hand, the value of $\mathrm{EC}_{50}$ decreased with an increasing extraction time. This was due to the influence of the operating extraction time inside temperature. The second-degree temperature $\left(\mathrm{A}^{2}\right)$ and extraction time $\left(\mathrm{B}^{2}\right)$ terms, that relate to the mathematical model were significant $(p<0.05)$. This might be the reason for the curvature of the surface. The effects of temperature and water to the Bene hull ratio on reduction power are shown in Fig. 2B. The $\mathrm{EC}_{50}$ value decreased with temperature and water to the Bene hull ratio. Curvature of the surface was due to the significance $(p<0.05)$ of the quadratic temperature term (Table 3). According to the total sum of squares, the importance of the independent variables on reduction power could be ranked in the order of interaction between temperature and time $(\mathrm{AB})$, the quadratic term of time $\left(\mathrm{B}^{2}\right)$, the interaction between temperature and water to the seed ratio $(A C)$, and the quadratic term of temperature $\left(\mathrm{A}^{2}\right)$.

A similar trend was reported by Hassas-Rodsari et al. (35) where the effect of a temperature increase from 110 to $160^{\circ} \mathrm{C}$ as the only variable factor on canola meal subcritical water extracts was studied with the conclusion that there was no significant difference between the reducing power of the studied temperatures. Moreover, Hossain et al. (25) reported a significant interaction between temperature and the solvent concentration in rosemary, marjoram and oregano. hen the extraction temperature and time were increased, the dielectric constant of water was decreased due to increased solubility of less polar compounds, resulting in an increase in the extract reducing power.

DPPH scavenging ability The response surface quadratic model for the DPPH scavenging ability had a significant Fvalue $(p<0.01)$, while the lack of fit test was not significant $(p>0.05)$. As a result, the regression model was appropriate for predicting the DPPH scavenging ability. The linear and quadratic effects for extraction temperature and time were significant $(p<0.05)$. Among the interaction terms, extraction time and temperature were significant $(p<0.05)$. The $R^{2}$ and adj- $R^{2}$ values for this response variable were 0.987 and 0.975 , respectively, indicating that the regression model was suitable to explain the behavior of the system. The relationship between the DPPH scavenging ability and the extraction parameters in a reduced quadratic model is shown in Eq. (5):

$$
\begin{aligned}
\mathrm{Y}= & +5779.74-50.98 \mathrm{X}_{1}-19.64 \mathrm{X}_{2}+0.15 \mathrm{X}_{1}^{2}+0.35 \mathrm{X}_{2}^{2} \\
& -0.096 \mathrm{X}_{1} \mathrm{X}_{2}
\end{aligned}
$$

To better understanding changes, contour plots and response surface plots for extraction variables against the DPPH scavenging ability were prepared (Fig. 3, 4). The DPPH scavenging ability was calculated based on $\mathrm{EC}_{50}$ values. In DPPH testing, antioxidants were able to reduce the stable purple DPPH radical to yellow diphenyl pricryl hydrazine. A low absorbance of the reaction mixture indicated a high free radical scavenging activity, which was interpreted from a graph of inhibition percentage against compound concentration. Achieving a low $\mathrm{EC}_{50}$ value was the purpose of this optimization. The temperature effect on the DPPH scavenging was significant $(p<0.05)$. The DPPH scavenging ability increased when the temperature increased, resulting in a low $\mathrm{EC}_{50}$ value. For the effect of extraction time on the DPPH scavenging ability, an increase in the extraction time increased the DPPH scavenging ability (Fig. 4A). Based on the interaction effect of the temperature-time extraction $(\mathrm{AB})$, the optimal point in the DPPH scavenging ability was near the surface center. The reasons for curvature of the surface were significant $(p<0.05)$ second-degree temperature $\left(\mathrm{A}^{2}\right)$ and extraction time $\left(\mathrm{B}^{2}\right)$ terms.
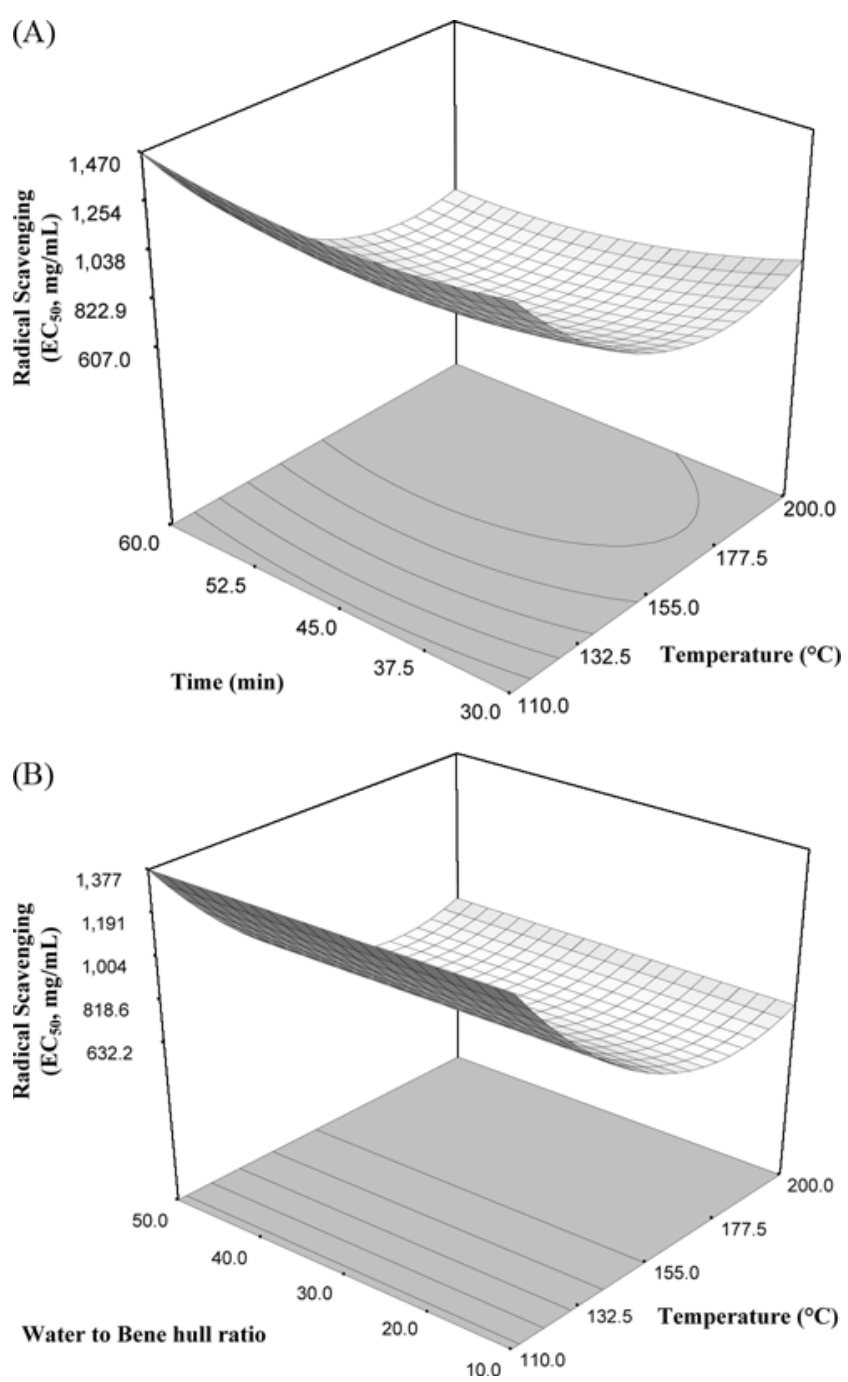

Fig. 3. Response surfaces and contour plots of the DPPH• scavenging ability $\left(\mathrm{EC}_{50}\right)$ of Bene hull SWE extracts as a function of (A) extraction time and temperature and (B) extraction temperature and water to the Bene hull ratio. 
The effect of extraction temperature and water to the Bene hull ratio on the DPPH scavenging ability is shown in Fig. 3B. The temperature variation was similar to extraction temperature-time surface changes (Fig. 4A). Changes in the solvent mixture had no significant $(p>0.05)$ effect on the DPPH scavenging ability. The scavenging ability remained constant at all of the mixing ratios (Fig. 4B). Generally, the temperature (A) was the most influential factor on the DPPH scavenging ability. However, other independent variables were ranked in the order of the quadratic terms of temperature $\left(\mathrm{A}^{2}\right)$, the interaction term between temperature-time $(\mathrm{AB})$, the linear term of time $(\mathrm{B})$, and the quadratic term of time $\left(\mathrm{B}^{2}\right)$. RodriguezMeizoso et al. (2) reported similar results.

The solubility of substances in water generally increases with temperature. A decrease in the dielectric constant of water at high temperatures and pressures is responsible for changes in the structure of electrolyte solutions. Compounds under these conditions result in an improvement in the DPPH scavenging ability, results of which were positively correlated with the reducing power. Extracts with a high DPPH scavenging ability also had a high reducing power. The obtained results were compatible with results reported by Farhoosh et al. (6) for Bene hull oil.
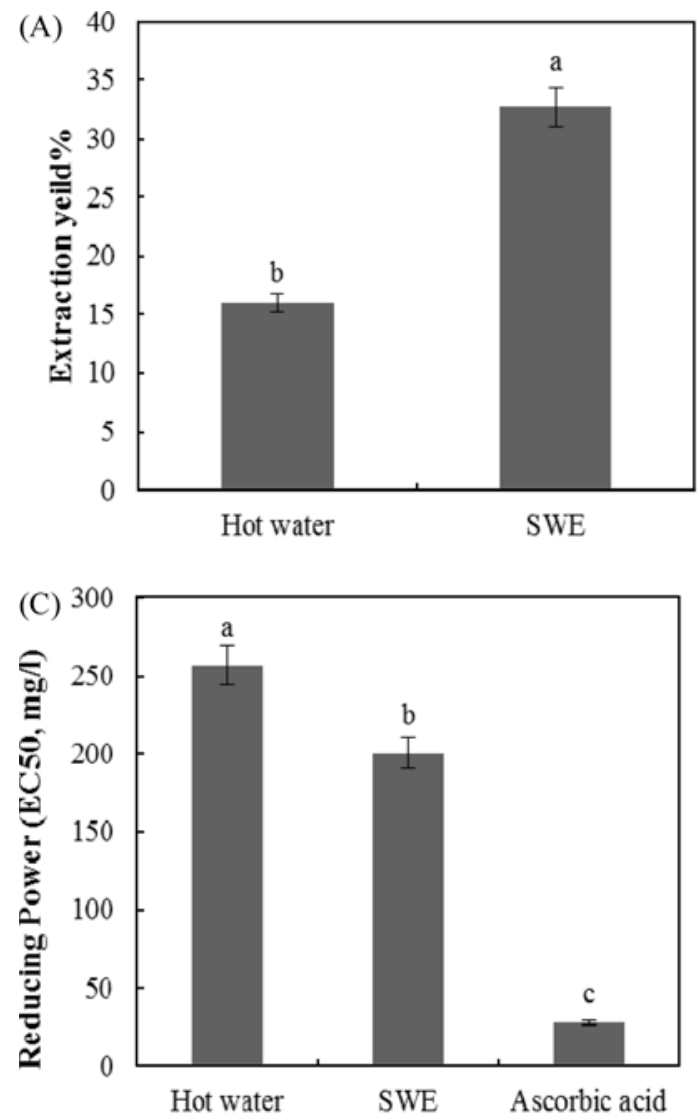

Optimization Optimum conditions for the subcritical water extraction procedure were determined in order to obtain a maximum polyphenolic content with a minimum $\mathrm{EC}_{50}$ value. The optimum conditions for extraction of Bene hull bioactive compounds were an extraction temperature of $196.8^{\circ} \mathrm{C}$, time $=52.6 \mathrm{~min}$, and water to the Bene hull ratio of 43.6:1. Under optimal conditions, the total phenolic content, the reducing power of $\mathrm{Fe}^{3+}$, and the DPPH scavenging ability were $2,284 \mathrm{mg}$ of GA/100 g of Bene hull, $200.161 \mathrm{mg} / \mathrm{L}$ (based on $\mathrm{EC}_{50}$ values), and 628.374 $\mathrm{mg} / \mathrm{L}$ (based on $\mathrm{EC}_{50}$ values), respectively.

Farhoosh et al. (8) studied Bene hull oil antioxidative properties and unsaponified matters materials using traditional extraction methods with a hexane solvent, and the amount of Bene hull oil polyphenolic compounds obtained was $310 \mathrm{mg} / \mathrm{kg}$. Furthermore, the DPPH scavenging ability (based on $\mathrm{EC}_{50}$ values) of Bene hull oil unsaponified material was $990 \mathrm{mg} / \mathrm{L}$. Comparing these reported results with the report of Hassas-Roudsari et al. (35) showed that the amount of polyphenolic compounds and the reducing power of Bene hull subcritical water extracts were more than for canola meal subcritical water extracts, while canola meal subcritical water extracts had a higher DPPH scavenging ability.

In this study, the extraction yield of Bene hull subcritical

(B)
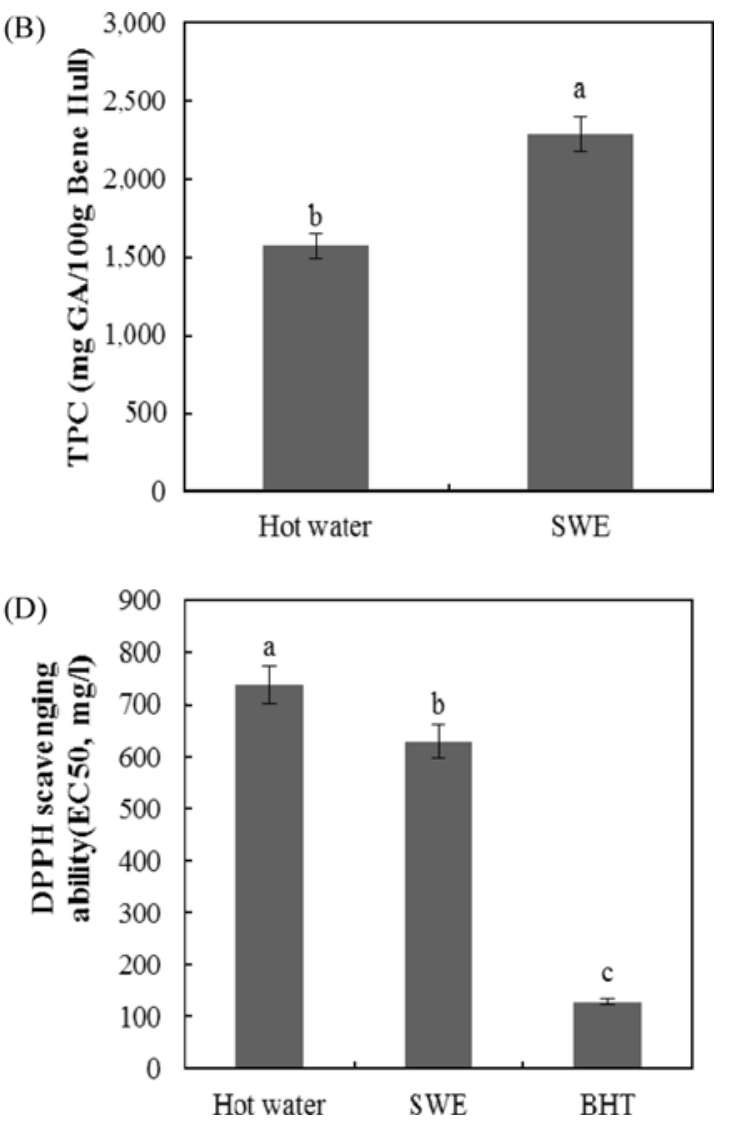

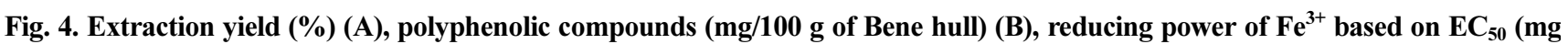
L) (C), and DPPH scavenging ability (D) based on $\mathrm{EC}_{50}(\mathrm{mg} / \mathrm{L})$ of hot water extracts $\left(85^{\circ} \mathrm{C}\right)$ of Pistacia atlantica in comparisor with SWE extracts and synthetic antioxidants. Duncan's test, $p<0.01$ 
water extracts was calculated as $32.72 \%$ at the optimal point, while the reducing power of ascorbic acid as an effective antioxidant was $27.454 \mathrm{mg} / \mathrm{L}$ (based on $\mathrm{EC}_{50}$ values). In other words, the reducing power of $200.161 \mathrm{mg} /$ $\mathrm{L}$ of Bene hull subcritical water extracts was equal to the reducing power of $27.474 \mathrm{mg} / \mathrm{L}$ of ascorbic acid. The DPPH scavenging ability of the standard BHT was calculated to be $127.589 \mathrm{mg} / \mathrm{L}$. Thus, the DPPH scavenging ability of $628.374 \mathrm{mg} / \mathrm{L}$ of Bene hull subcritical water extracts was equal to $127.859 \mathrm{mg} / \mathrm{L}$ of BHT. This result was expected because both ascorbic acid and BHT are pure antioxidants while Bene hull subcritical water extracts were not pure and contained other bioactive compounds and antioxidants. Yogendra Kumar et al. (18) reported that the ascorbic acid reducing power as a pure antioxidant was more than for sea buckthorn leaf subcritical water extracts.

Hot water extraction $\left(\mathbf{8 5}^{\circ} \mathrm{C}\right)$ Results for subcritical water extraction were compared with results obtained using a hot water extraction method at $85^{\circ} \mathrm{C}$ (Fig. 5). The average extraction yield, total phenolic content, and reducing power of both $\mathrm{Fe}^{3+}$ and DPPH for hot water extracts with 3 replicates were $15.95 \%, 1564.8 \mathrm{mg} / 100 \mathrm{~g}$ of Bene hull, $256.44 \mathrm{mg} / \mathrm{L}$ (based on $\mathrm{EC}_{50}$ values), and $737.233 \mathrm{mg} / \mathrm{L}$ (based on $\mathrm{EC}_{50}$ values), respectively. A significant difference $(p<0.01)$ was observed between the 2 extraction methods. The subcritical water extraction method had a higher extraction yield and an antioxidant capacity than the traditional hot water extraction method.

HPLC analysis of the Bene hull SWE extracts Chromatograms of SWE extracts from Bene hull obtained under optimal conditions (temperature $=196.8^{\circ} \mathrm{C}$, time $=$
$52.6 \mathrm{~min}$, and water to seed ratio $=1: 43.6$ ) are shown in Fig. 5. By comparison of the retention times $\left(R_{t}\right)$ of the experimental chromatograms with a standard chromatogram, that obtained from some standard compounds. the HPLC chromatogram of Bene hull SWE extracts under optimal conditions contained epicatechin (4.05\%), chlorogensaure $(5.86 \%)$, kaffesaure $(0.51 \%)$, flavanomarein $(0.28 \%)$, ethyl vanillin $(0.49 \%)$, and apigenin 7 -glucoside $(0.55 \%)$. The Bene hull SWE extracts under optimal conditions included $51.81 \%$ of a component with $\mathrm{R}_{\mathrm{t}}=4.2 \mathrm{~min}$ for the main phenolic component. Furthermore, the most important unknown compound obtained comprised $8.92 \%$ of the total components with $\mathrm{R}_{\mathrm{t}}=1.97 \mathrm{~min}$, followed by an unknown compound that comprised $8.71 \%$ of the total components with $\mathrm{R}_{\mathrm{t}}=5.05 \mathrm{~min}$, and a third unknown compound that comprised $7.24 \%$ of the total components with $\mathrm{R}_{\mathrm{t}}=2.7 \mathrm{~min}$.

Overall, the amount of polyphenolic compounds obtained from HPLC analysis was calculated to be $31,865.65 \mathrm{mg} / \mathrm{kg}$ using syringic acid as an internal standard. This amount was almost equal to the amount obtained using a chemical assay considering the conversion ratio of syringic acid to GA. The presence of phenolic compounds with a mediumhigh polarity was indicated by these results. Similar results have been reported by Rodriguez-Meizoso et al. (36). The presence of such compounds can partially explain the Bene hull SWE extract antioxidative activities.

Acknowledgments The author acknowledges Research Institute of Food Science and Technology (RIFST) for financial and technical support.

Disclosure The authors declare no conflict of interest.

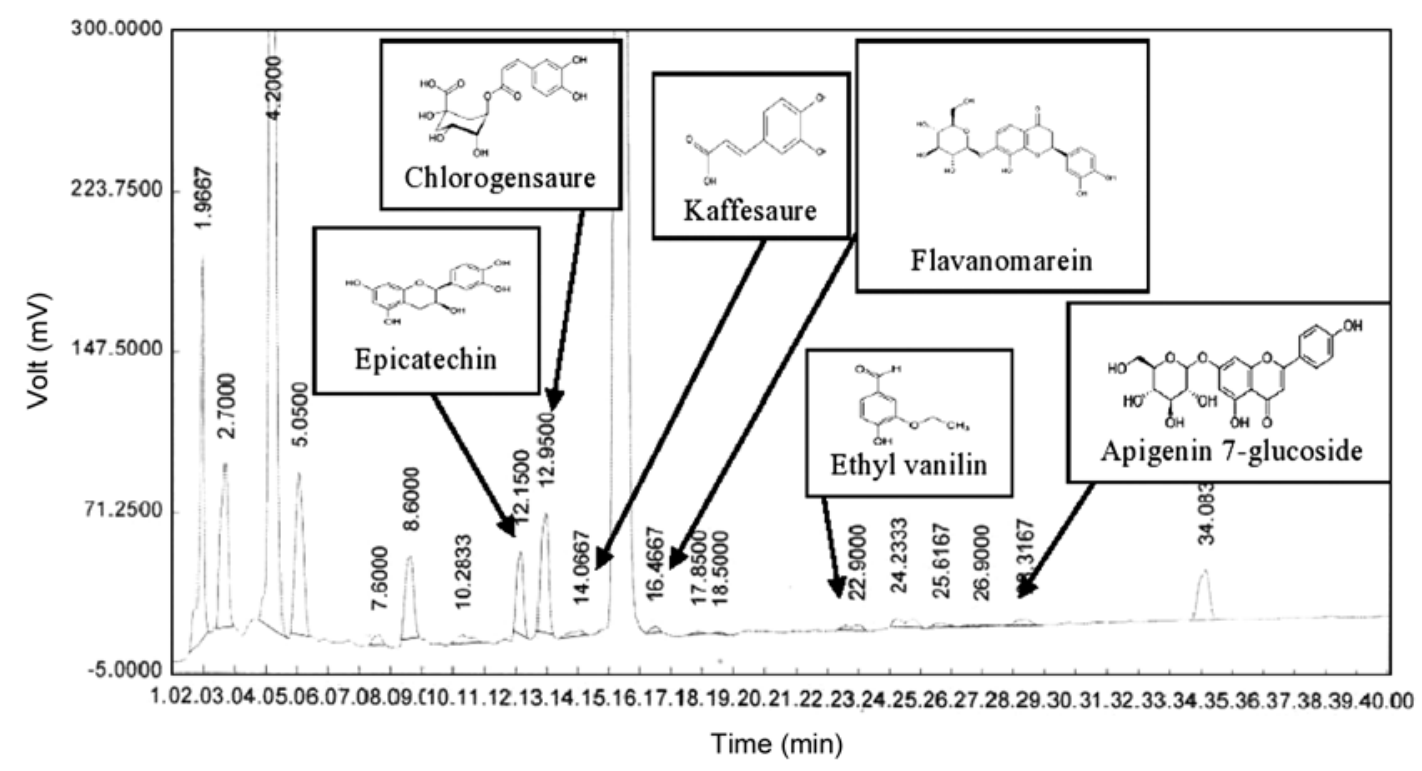

Fig. 5. HPLC chromatogram for subcritical water extracts of Pistacia atlantica for analysis of phenolic compounds. 


\section{References}

1. Madhavi DL, Deshpande SS, Salunkhe DK. Food Antioxidants: Technological: Toxicological and Health Perspectives. Marcel Dekker, New York, NY, USA (1996)

2. Rodriguez-Meizoso I, Marin FR, Herrero M, Senorans FJ, Reglero G Cifuentes A, Ibanez E. Subcritical water extraction of nutraceuticals with antioxidant activity from oregano. Chemical and functional characterization. J. Pharmaceut. Biomed. 41: 1560-1565 (2006)

3. Skerget M, Kotnik P, Hadolin M, Hras AR, Simonic M, Knez Z. Phenols. Proanthocyanidins, flavones and flavonols in some plant materials and their antioxidant activities. Food Chem. 89: 191-198 (2005)

4. Sabeti, H. Forests, trees, and shrubs of Iran. Iran University of Science and Technology Press, Tehran, Iran (1994)

5. Daneshrad A, Aynechi Y. Chemical studies of the oil from pistacia nuts growing wild in Iran. JAOCS 57: 248-249 (1980)

6. Farhoosh R, Khodaparast MH, Sharif A. Bene hull oil as a highly stable and antioxidative vegetable oil. Eur. J. Lipid. Sci. Tech. 111: 1259-1265 (2009)

7. Farhoosh R, Tavassoli-Kafrani MH. Polar compounds distribution of sunflower oil as affected by unsaponifiable matters of Bene hull oil (BHO) and tertiary-butylhydroquinone (TBHQ) during deepfrying. Food Chem. 122: 381-385 (2010)

8. Farhoosh R, Tavassoli-Kafrani MH, Sharif A. Antioxidant activity of the fractions separated from the unsaponifiable matters of bene hull oil. Food Chem. 126: 583-589 (2011)

9. Farhoosh R, Tavassoli-Kafrani MH, Sharif A. Antioxidant activity of sesame, rice bran, and bene hull oils and their unsaponifiable matters. Eur. J. Lipid. Sci. Tech. 113: 506-512 (2011)

10. Ramos L, Kristenson EM, Brinkman UAT. Current use of pressurised liquid extraction and subcritical water extraction in environmental analysis. J. Chromatogr. 975: 3-29 (2002)

11. Carabias-Martinez R, Rodriguez-Gonzalo E, Revilla-Ruiz P, HernandezMendez J. Pressurized liquid extraction in the analysis of food and biological samples. J. Chromatogr. 1089: 1-17 (2005)

12. Teo CC, Tan SN, Yong JWH, Hew CS, Ong ES. Pressurized hot water extraction (PHWE). J. Chromatogr. 1217: 2484-2494 (2010)

13. Herrero M, Cifuentes A, Ibanez E. Sub- and supercritical fluid extraction of functional ingredients from different natural sources: Plants, food-by-products, algae and microalgae: A review. Food Chem. 98: 136-148 (2006)

14. Rostagno MA, Villares A, Guillamon E, Garcia-Lafuente A, Martinez JA. Sample preparation for the analysis of isoflavones from soybeans and soy foods. J. Chromatogr. 1216: 229 (2009)

15. Wiboonsirikul J. Adachi S. Extraction of functional substances from agricultural products or by-products by subcritical water treatment Food Sci. Technol. Res. 14: 319-328 (2008)

16. Kim JW, Nagaoka T, Ishida Y, Hasegawa T, Kitagawa K, Lee SC. Subcritical water extraction of nutraceutical compounds from citrus pomaces. Separ. Sci. Technol. 44: 2598-2608 (2009)

17. Kim WJ, Kim J, Veriansyah B, Kim JD, Lee YW, Oh SG Tjandrawinata RR. Extraction of bioactive compounds from Centella asiatica using subcritical water. J. Supercrit. Fluid. 48: 211216 (2009)

18. Yogendra Kumar MS, Dutta R, Prasad D, Misra K. Subcritical water extraction of antioxidant compounds from Seabuckthorn (Hippophae rhamnoides) leaves for the comparative evaluation of antioxidant activity. Food Chem. 127: 1309-1316 (2011)

19. Lee KA, Kim KT, Nah SY, Chung MS, Cho SW, Paik HD. Antimicrobial and antioxidative effects of onion peel extracted by the subcritical water. Food Sci. Biotechnol. 20: 543-548 (2011)

20. Ibanez E, Kubatova A, Senorans FJ, Cavero S, Reglero G, Hawthorne SB. Subcritical water extraction of antioxidant compounds from rosemary plants. Food Chem. 51: 375-382 (2003)
21. Rangsriwong P, Rangkadilok N, Satayavivad J, Goto M, Shotipruk A. Subcritical water extraction of polyphenolic compounds from Terminalia chebula Retz. fruits. Sep. Purif. Technol. 66: 51-56 (2009)

22. He L, Zhang X, Xu H, Xu C, Yuan F, Knez Z, Novak Z, Gao Y. Subcritical water extraction of phenolic compounds from pomegranate (Punica granatum L.) seed residues and investigation into their antioxidant activities with HPLC-ABTS ${ }^{+}$assay. Food Bioprod. Process. 90: 215-223 (2012)

23. Garcia-Marino M, Rivas-Gonzalo JC, Ibanez E, Garcia-Moreno C. Recovery of catechins and proanthocyanidins from winery byproducts using subcritical water extraction. Anal. Chim. Acta 563: 4450 (2006)

24. Vuataz L. Statistical procedures in food research, In: Statistical Procedures in Food. Piggott JR (ed). Elsevier Applied Science, London, UK (1986)

25. Hossain MB, Barry-Ryan C, Martin-Diana AB, Brunton NP. Optimisation of accelerated solvent extraction of antioxidant compounds from rosemary (Rosmarinus officinalis L.), marjoram (Origanum majorana L.) and oregano (Origanum vulgare L.) using response surface methodology. Food Chem. 126: 339-346 (2011)

26. Gelmez N, Kincal NS, Yener ME. Optimization of supercritical carbon dioxide extraction of antioxidants from roasted wheat germ based on yield, total phenolic and tocopherol contents, and antioxidant activities of the extracs. J. Supercrit. Fluid. 48: 217-224 (2009)

27. Teng H, Choi YH. Optimization of extraction of bioactive alkaloids and antioxidants from Rhizome Coptidis (Coptis Chinensis Franch) by using response surface methodology. Food Sci. Biotechnol. 21: 799-806 (2012)

28. Atkinson AC, Donev AN. Optimum experimental designs. Oxford University Press. Oxford, UK. pp. 132-189 (1992)

29. Bergeron C, Gafner S, Clausen E, Carrier DJ. Comparison of the chemical composition of extracts from Scutellaria lateriflora using accelerated solvent extraction and supercritical fluid extraction versus standard hot water or $70 \%$ ethanol extraction. J. Agr. Food Chem. 53: 3076-3080 (2005)

30. Singh RP, Murthy KNC, Jayaprakasha GK. Studies on the antioxidant activity of pomegranate (Punica granatum) peel and seed extracts using in vitro models. J. Agr. Food Chem. 50: 81-86 (2002)

31. Barros L, Ferreira M, Queiros B, Ferreira I, Baptista P. Total phenols, ascorbic acid, $\beta$-carotene, and lycopene in Portuguese wild edible mushrooms and their antioxidant activities. Food Chem. 103: 413-419 (2007)

32. International Olive Council. Determination of biophenols in olive oils by HPLC. Available from: http://www.internationaloliveoil. org/ documents/viewfile/4141-met29eng. Accessed Nov. 29, 2009.

33. Gugliucci A, Markowicz-Bastos DH, Schulze J, Ferreira-Souza MF. Caffeic and chloreogenic acids in Ilex paraguarensis extracts are the main inhibitors of AGE generation by methylglyoxal in model proteins. Fitoterapia 80: 339-344 (2009)

34. Plaza M, Amigo-Benavent M, Del Castillo MD, Ibanez E, Herrero M. Facts about the formation of new antioxidants in natural samples after subcritical water extraction. Food Res. Int. 43: 2341-2348 (2010)

35. Hassas-Roudsari M, Chang PR, Pegg RB, Tyler RT. Antioxidant capacity of bioactives extracted from canola meal by subcritical water, ethanolic and hot water extraction. Food Chem. 114: 717-726 (2009)

36. Rodriguez-Meizoso I, Jaime L, Santoyo S, Senorans FJ, Cifuentes A, Ibanez E. Subcritical water extraction and characterization of bioactive compounds from Haematococcus pluviales microalga. J. Pharmaceut. Biomed. 51: 456-463 (2010) 